\title{
Correction to: on the way to understanding binge watching behavior: the over-estimated role of involvement
}

\author{
Jani Merikivi $^{1,2}$ - Antti Salovaara ${ }^{2} \cdot$ Matti Mäntymäki $^{3} \cdot$ Lilong Zhang $^{1}$
}

Published online: 15 November 2017

(C) Institute of Applied Informatics at University of Leipzig 2017

\section{Correction to: Electron Markets}

https://doi.org/10.1007/s12525-017-0271-4

The original version of this paper unfortunately captured the affiliation of Dr. Matti Mäntymäki incorrectly and is now corrected on this article.

The online version of the original article can be found at https://doi.org/ $10.1007 / \mathrm{s} 12525-017-0271-4$

Jani Merikivi

jani.merikivi@aalto.fi

1 National Research Center of Cultural Studies, Central China Normal University,

152 Luoyu road, Wuhan, Hubei, China

2 Department of Information and Service Economy, Aalto University, School of Business,

Runeberginkatu 14-16, 00100 Helsinki, Finland

3 University of Turku, Turku School of Economics, Rehtorinpellonkatu 3, Turku, Finland 